\title{
Neuro - Fuzzy Modeling of an Eco-friendly Melting Furnace Parameters using Bio-fuels for the Agile Production of Quality Castings
}

\author{
Purshottam Kumar \\ Dayalbagh Educational Institute \\ Dayalbagh, Agra-282005, U.P., INDIA - 282110
}

\author{
Ranjit Singh \\ Dayalbagh Educational Institute \\ Dayalbagh, Agra-282005, U.P., INDIA - 282110
}

\begin{abstract}
In this paper neuro-fuzzy technique is used for the first time in modeling eco-friendly furnace parameters to predict the melting rate of the molten metal required to produce homogenous and quality castings. The relationship between the process variables (input) viz. flame temperature, preheat air temperature, rotational speed of the furnace dome, percentage of excess air, melting time, fuel consumption and melting rate (output) is very complex and is agreeable to neuro-fuzzy approach. The neuro-fuzzy model has been developed out of training data obtained from the series of experimentation carried out on eco-friendly self designed and developed $200 \mathrm{~kg}$ capacity rotary furnace using bio-fuels. The results provided by neuro-fuzzy model compares well with the experimental data. This work has considerable implications in selection and control of process variables in real time and ability to achieve energy and material savings, quality improvement and development of homogeneous properties throughout the casting and is a step towards agile manufacturing.
\end{abstract}

\section{General Terms}

Neuro-Fuzzy, ANFIS, Neural Network

\section{Keywords}

Neuro-Fuzzy, Rotary Furnace, Bio-fuel, Artificial Neural Network (ANN), Adaptive Network - based Fuzzy Inference System (ANFIS), Agile Manufacturing Systems (AMS).

\section{INTRODUCTION}

AGILE Manufacturing Systems (AMS) are respond to rapid changes in designs and demand without intervention by humans. Agility, specifically, has the following principal components: quality, speed to market, widening customer choice and expectation, the competitive priorities of responsiveness, new product introduction, readiness for change, respect for human knowledge and skills, and a synthesized use of the developed and well-known technologies and methods of manufacturing. In order to take advantage of speed to market and new product introductions, management must invest in technologies that confer operational flexibility.

So as to respond to changing demand scenarios, the system must be equipped with a comprehensive manufacturing planning and control system that incorporates vast amounts of manufacturing knowledge in a form that is accessible rapidly. The design and implementation of these systems is one of the major challenges faced by today's manufacturing engineers [1-3].
The basic idea of Rotary furnace technique is of using a dome rotating continuously to create homogeneity in the casting. The rotary furnace consists of a cylindrical structure, which rotates continuously about its axis is shown in figure 1 . The furnace can be run by a variety of fuels but at present we are using Jatropha (bio-fuel) blended with diesel for firing the furnace fired furnace. This technique suits the conditions and requirements of the local foundries in terms of the cost of castings produced as well as their quality. Moreover the pollutants emitted by the furnace are well within the range specified by the Central Pollution Control Board (C.P.C.B.) of India.

The Rotary furnace is the most versatile and economical mode of melting iron in ferrous foundries. But it is very strange that a very little information is available in the form of literature on this furnace.

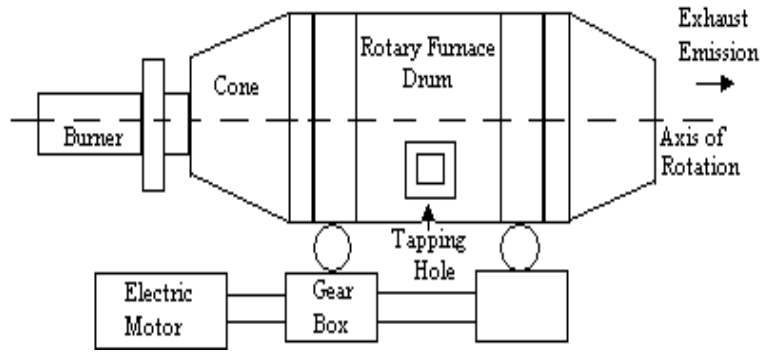

Fig. 1. Layout of Rotary Furnace

There are a number of variables controllable to varying degrees which affect the quality and composition of the outcoming molten metal. These variables, such as flame temperature, preheat air temperature, rotational speed, excess air percentage, melting time, fuel consumption and melting rate play significant role in determining the molten metal's properties and should be controlled throughout the melting process. However, even an experienced operator may find it difficult to select the optimum input parameters which would yield ideal molten metal and often he may choose them by guessing which may not be effective and economical.

In order to meet this demand, a neuro-fuzzy model is developed that correlates well with the experimental data. This work also has implications in the selection and control of process variables in real time and ability to achieve energy and material savings, quality improvement and development of homogeneous properties throughout the casting process [4]. 


\section{NEURO-FUZZY SYSTEMS}

Neuro-fuzzy systems belong to a newly developed class of hybrid intelligent systems that combine the main features of artificial neural networks with those of fuzzy logic, using heuristic learning strategies derived from the domain of neural network theory to support the development of a fuzzy system. Modern neuro-fuzzy systems usually are represented as a multilayer feed-forward neural network. In neuro-fuzzy models, connection weights, propagation and activation functions differ from common neural networks.

The neuro-fuzzy system is capable of extracting fuzzy knowledge from numerical data and linguistic data into the system. The goal here is to avoid difficulties encountered in applying fuzzy logic for systems represented by numerical knowledge (data sets), or in applying neural networks for systems presented by linguistic information (fuzzy sets). Neither fuzzy reasoning systems nor neural networks are by themselves capable of solving problems involving at the same time both linguistic and numerical knowledge. A number of researchers have used the term hybrid systems to depict systems that involve in some ways both fuzzy logic and neural network features [5-7].

Neuro-fuzzy systems overcome the limitations of artificial neural networks (ANN) and fuzzy system. A neuro-fuzzy system is trained by a learning algorithm derived from neural network theory. The (heuristic) learning procedure operates on local information, and causes only local modifications in the underlying fuzzy system. The learning process is not knowledge-based, but data-driven.

A neuro-fuzzy system can be viewed as a special multi-layer, feed-forward neural network. The first layer represents input variables, the middle (hidden) layer(s) represent(s) fuzzy rules and the last layer represents output variables. Fuzzy sets are encoded as (fuzzy) connection weights. A neuro-fuzzy system can always be interpreted (i.e., before, during and after learning) as a system of fuzzy rules. It is possible both to create the system out of training data from scratch and to initialize it by prior knowledge in the form of fuzzy rules.

A neuro-fuzzy system approximates an n-dimensional (unknown) function that is given partially by the training data. It is possible to view a fuzzy system as a special neural network and to apply a learning algorithm directly (hybrid models).

Recently, several approaches were suggested for generating the fuzzy rules from numerical data automatically. Most notable is Jang's Adaptive Network - based Fuzzy Inference System (ANFIS) [8].

ANFIS Developed by Jang, is an extension of the Takagi, Sugeno and Kang (TSK) fuzzy model [9]. ANFIS represents a neural network approach to the design of fuzzy inference systems. An ANFIS network makes use of a supervised learning algorithm to determine a non-linear model of the input-output function, which is represented by a training set of numerical data. Because, under proper conditions it can be used as a universal approximator, an ANFIS network is suited particularly for solving function approximation problems in several engineering fields. The present model allows the fuzzy system to learn the parameters using hybrid learning algorithm [10-13].

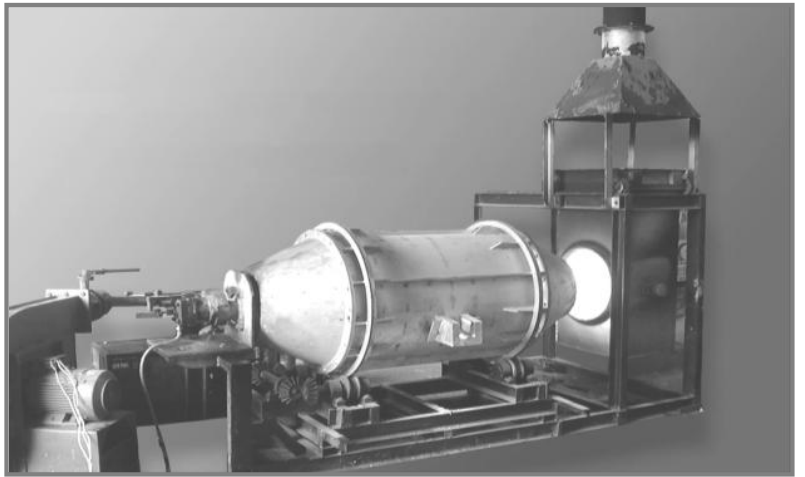

Fig. 2. Self Designed and Developed Rotary Furnace at Foundry Shop, Faculty of Engineering, Dayalbagh Educational Institute, Dayalbagh, Agra

\section{NEURO-FUZZY MODELING OF ROTARY FURNACE PARAMETERS}

In this section, the Neuro-fuzzy modeling of rotary furnace parameters is described. The data is obtained from the experiments conducted on a self-designed and developed furnace as shown in the Figure 2, at Foundry Shop, Faculty of Engineering, D.E.I., Dayalbagh, Agra, INDIA and is used to train the neuro-fuzzy model.

In the experimentation $200 \mathrm{~kg}$. of the charge is melted in the rotary furnace. A Circular burner is used for burning Bio fuel which is used as a fuel. Total 201 numbers of experiments were conducted at different percentages of excess air, varying from $10 \%$ to $50 \%$ and varying in the amount of air preheat from $200^{\circ} \mathrm{C}$ to $400^{\circ} \mathrm{C}$ [14-15].

\section{Architecture of ANFIS}

The ANFIS is a fuzzy Sugeno Model put in the framework of adaptive systems to facilitate learning and adaptation. Such framework makes the ANFIS modeling more systematic and less reliant on expert knowledge. A six input neuro - fuzzy network architecture with five layers is shown in the figure 3.

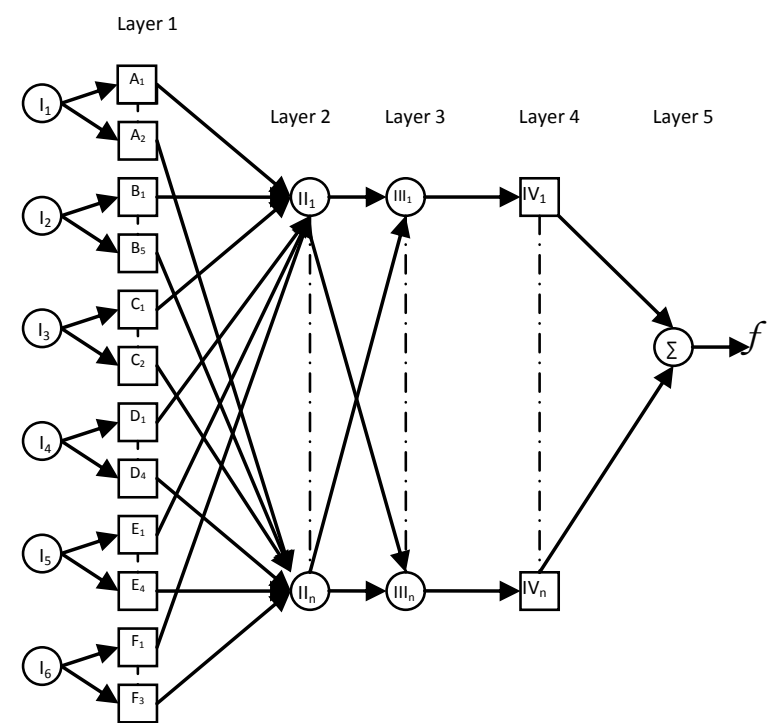

Fig. 3. An ANFIS Architecture used in predicting results The data set comprises of six input viz. percentage of excess air in \% (EA), flame temperature in ${ }^{\circ} \mathrm{C}(\mathrm{FT})$, rotational speed 
in RPM (RS), melting time in Minutes (MT), preheat air temp in ${ }^{\circ} \mathrm{C}$ (PAT), fuel consumed in Liters (FC) and one output Melting rate (MT/hr.).

The description of each layer is given below:

Layer 1: Every node in this layer is a square node and each node outputs the membership value of input.

Layer 2: The function of node in this layer is to multiply the incoming signals and produce the product of all inputs to compute the rule matching factor.

Each node output represents the firing strength of a rule.

Layer 3: The input firing strength is normalized in this layer and output is called normalized firing strengths.

Layer 4: Every node $i$ in this layer is a parameterized function. Parameters in this layer are referred as consequent parameters.

Layer 5: The single node in this layer computes the overall output as the summation of all incoming signals

The system is initialized with a number of membership functions and a rule base. Learning consists of two separate passes. In the forward pass, the consequent parameters are determined by least square method and antecedent parameters are updated by a gradient descent algorithm in the backward pass.

\section{ANFIS Computational Complexity}

\begin{tabular}{llll}
\hline Layer \# & L-Type & \# Nodes & \# Parameter \\
\hline Layer 1 & Value & $\left(\mathrm{p}^{*} \mathrm{n}\right)$ & $3 *\left(\mathrm{p}^{*} \mathrm{n}\right)=|\mathrm{S} 1|$ \\
Layer 2 & Rules & $\mathrm{p}^{\mathrm{n}}$ & 0 \\
Layer 3 & Normalize & $\mathrm{p}^{\mathrm{n}}$ & 0 \\
Layer 4 & Lin. Function & $\mathrm{p}^{\mathrm{n}}$ & $(\mathrm{n}+1)^{*} \mathrm{p}^{\mathrm{n}}=|\mathrm{S} 2|$ \\
Layer 5 & Sum & 1 & 0
\end{tabular}

Where:

- $\mathrm{p}$ is the number of fuzzy partitions of each variable

- $\mathrm{n}$ is the number of input variables

- $\mathrm{S} 1$ represents the fuzzy partitions used in the rules LHS

- S2 represents the coefficients of the linear functions in the rules RHS

The forward pass of the learning algorithm continues up to nodes at layer 4 and consequent parameters are determined by the method of least squares. In the backward pass, the error signal propagates backward to update the premise parameters by gradient descent $[8,9,16]$. The shape of the membership functions to be used in ANFIS depends on parameters, and changing these parameters change the shape of the membership function. Instead of just looking at the data to choose the membership function parameters, we selected 3 different memberships function (MF) parameters using ANFIS GUI. The 3 Membership function used in ANFIS are (a) triangular membership function (trimf), (b) Gaussian membership function (gaussmf), (c) difference between two sigmoidal functions (dsigmf) and the simulkated results are calculated for the data obtained through the experiment. Inspite of fixing the number of epoch we used different number of epoch for different MF until the error is reduced to its global minima

The training information is as follows:
Table: 1

\begin{tabular}{|c|c|}
\hline \multicolumn{2}{|c|}{ ANFIS Information } \\
\hline Total no of inputs & 6 \\
\hline $\begin{array}{l}\text { No of membership Function for } \\
\text { each input }\end{array}$ & {$\left[\begin{array}{llllll}2 & 5 & 2 & 4 & 4 & 3\end{array}\right]$} \\
\hline \multirow{3}{*}{ Membership Function used } & 1. GAUSSMF \\
\hline & 2. TRIMF \\
\hline & 3. DSIGMF \\
\hline Number of nodes & 1969 \\
\hline Number of linear parameters & 960 \\
\hline Number of nonlinear parameters & 60 \\
\hline Total number of parameters & 1020 \\
\hline Number of training data pairs & 132 \\
\hline Number of checking data pairs & 69 \\
\hline Number of fuzzy rules & 960 \\
\hline
\end{tabular}

The ANFIS structure shown in figure 3 was implemented by using MATLAB software package (MATLAB version 7.0 with fuzzy logic toolbox) using 201 experimental data sets, among which 132 data sets are used for training and rest 69 are used validating the model given in Table 4.

\section{SIMULATION RESULTS}

In training model, number of membership functions

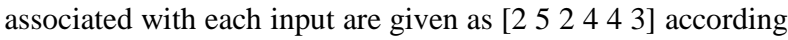
to the preference of input on output. The same model is run on same MF (trimf, gaussmf and dsigmf) and it is found that the predicted values by ANFIS model used in this work are much closer to the experimental values as can be observed from the results. The chart between RMS error with number of epoch for GAUSSMF, DSIGMF, TRIMF is shown in Figure 4, Figure 5 and Figure 6 respectively. The Error chart shows that the RMS error converges rapidly with minimum number of epoch for TRIMF in comparison with GAUSSMF, while in DSIGMF the RMS error curve do not converge till 200 epochs, and the computational time too increases with each epoch. The results in Table 2 and Figure 7 showing difference between desired and predicted values by the three membership function are also satisfying RMS chart shown in Figure 4, Figure 5 and Figure 6. Some of the data sets obtained by experiments on Rotary Furnace for various parameters are listed in Table 4. A comparison of experimental results and the estimated values reported by ANFIS model are listed in Table 3.

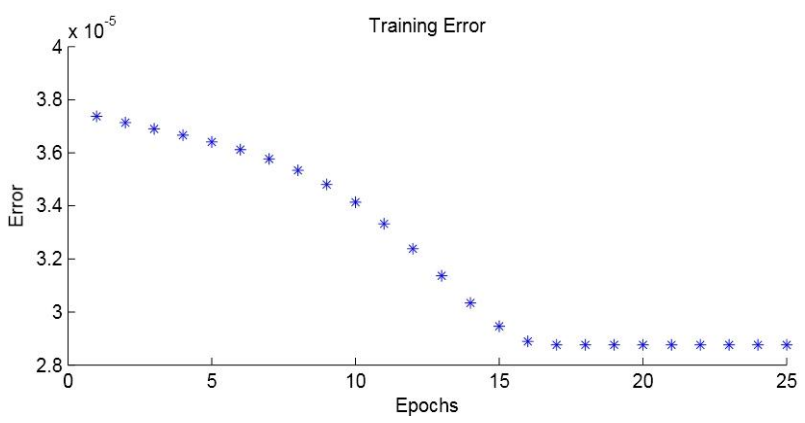

Fig. 4. Graph between RMS Error and number of Epochs using Gauss 


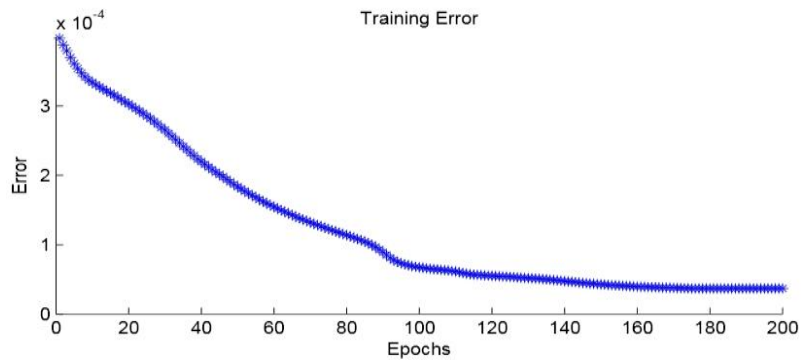

Fig 5: Graph between RMS Error and number of Epochs using DSIGMF

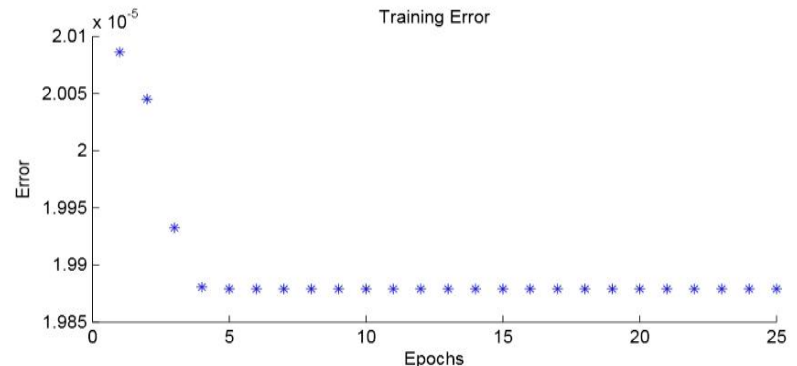

Fig 6: Graph between RMS Error and number of Epochs using TRIMF
Table: 2

Difference between desired and predicted values

\begin{tabular}{|l|l|l|}
\hline \multirow{4}{*}{ Gauss error in \% } & Average & 0.00392579 \\
\cline { 2 - 3 } & Minimum & 0 \\
\cline { 2 - 3 } & Maximum & 0.1844907 \\
\hline \multirow{4}{*}{ DSIGMF error in \% } & Average & 0.00532441 \\
\cline { 2 - 3 } & Minimum & 0 \\
\cline { 2 - 3 } & Maximum & -0.299267598 \\
\hline \multirow{3}{*}{ TRIMF error in \% } & Average & 0.002858178 \\
\cline { 2 - 3 } & Minimum & -0.0000280 \\
\cline { 2 - 3 } & Maximum & 0.148277499 \\
\hline
\end{tabular}

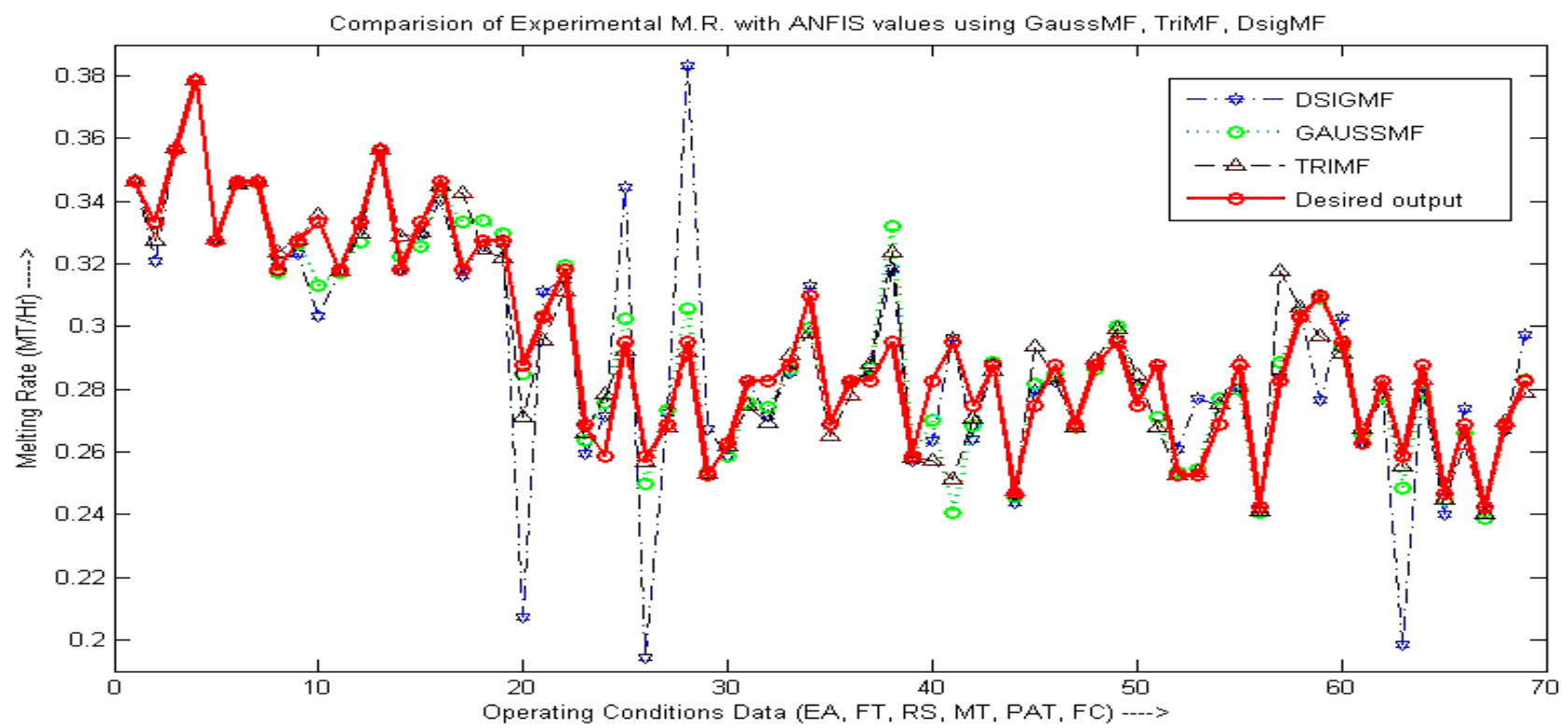

Fig 7. Comparison of 3 Membership Function with desired output

\section{CONCLUSION}

The developed neuro-fuzzy model in this paper can effectively estimate the melting rate based on input process variables viz. flame temperature, preheat air temperature, rotational speed of the furnace drum, excess air percentage, melting time, and fuel consumption that correlates well with the experimental values. It is found that for our model does not give satisfactory result with DSIGMF in comparisons to GAUSSMF and TRIMF as the error is high in case of DSIGMF. Since the average error is minimum in the case of TRIMF. So, this may be selected as the membership function for evaluating the melting rate. The results demonstrate that the ANFIS can be applied successfully and provide high accuracy and reliability for estimating the melting rate of the molten metal in foundries. This technique easily captures the intricate relationship between various process parameters and can be easily integrated into existing manufacturing environment and also opens new avenues of parameter estimation, function approximation, optimization and online control of complex manufacturing systems.

\section{REFERENCES}

[1] S. L. Goldman, R. N. Nagel, and K. Preiss, "Agile Competitors and Virtual Organizations: Strategies for Enriching the Customer", Van Nostrand Reinhold, New York, 1995

[2] Y. Y. Yusuf, M. Sarhadi, and A. Gunasekaran, "Agile Manufacturing: The Drivers, Concepts and Attributes", International Journal of Production Economics, Vol. 62, 1999, pp. 33-43.

[3] P. T. Kidd, "Agile Manufacturing: Forging New Frontiers", Addison - Wesley Reading, M.A., 1994. 
[4] R. Singh, G. Das, and R. Setia, "Parametric Modeling of a Rotary Furnace for Agile Production of Castings with Artificial Neural Networks," International Journal of Agile Manufacturing, Vol. 10, Issue 2, 2007, pp. 137147

[5] H. R. Berenji, and P. Khedkar, "Learning and Tuning Fuzzy Logic Controllers Through Reinforcements", IEEE Trans. Neural Networks, Vol. 3(5), 1992, pp. 724740 .

[6] J. J. Buckley, and Y. Hayashi, "Fuzzy Neural Networks: A Survey", Fuzzy Sets and Systems, Vol. 66, 1994, pp. $1-13$.

[7] J. J. Buckley, and Y. Hayashi, "Neural Networks for Fuzzy Systems", Fuzzy Sets and Systems, Vol. 71, 1992, pp. 265-276.

[8] J. S. R. Jang, "ANFIS: Adaptive-Network-Based Fuzzy Inference Systems" IEEE Transaction on Systems, Man \& Cybernetics, Vol. 23, 1993, pp. 665-685.

[9] T. Takagi, and M. Sugeno, "Fuzzy Identification of Systems and its Application to Modeling and Control", IEEE Transaction on Systems, Man \& Cybernetics, Vol. 15,1985 , pp. 116-132

[10] S. K. Halgamuge, and M. Glesner, "Neural Networks in Designing Fuzzy Systems for Real World Applications", Fuzzy Sets and Systems, Vol. 65, 1994, pp. 1-12.
[11] D. Nauck, and K. Kruse, "Designing Neuro - fuzzy Systems Through Back - propagation". In Witold Pedrycz, editor, Fuzzy Modelling: Paradigms and Practice, 1996, pp. 203-228, Kluwer, Boston.

[12] D. Nauck, and K. Kruse, "Neuro-fuzzy Systems Research and Applications Outside of Japan" (in Japanese), Fuzzy-Neural Networks (in Japanese), Soft Computing Series, 1996, pp. 108-134, Asakura Publications, Tokyo.

[13] S. K. Halgamuge, and M. Glesner, "Neural Networks in Designing Fuzzy Systems for Real World Applications," Fuzzy Sets and Systems, Vol. 65, 1994, pp. 1-12.

[14] R. Singh, R. Setia, and G. Das, "Modeling and Optimization of Rotary Furnace Parameters using Artificial Neural Networks and Genetic Evolutionary Algorithms," Proceedings of 31st National Systems Conference, MIT, Manipal, December 14-15, 2007, P.No.-75

[15] R. Singh, G. Das, and R. K. Jain, "Modeling and Optimization of Rotary Furnace Parameters using Regression and Numerical Techniques," Proceedings of 68th World Foundry Congress \& 56th Indian Foundry Congress, Chennai Trade Centre, Chennai, February $7-$ 10, 2008, P.No. OP-62, pp. 333-339.

[16] M. Sugeno, and G. T. Kang, "Structure Identification of Fuzzy Model”, Fuzzy Sets and Systems, Vol. 28, 1998, pp. $15-33$

TABLE : 3

\begin{tabular}{|c|c|c|c|c|c|c|c|}
\hline \multirow{3}{*}{$\begin{array}{l}\text { Sl. } \\
\text { No. }\end{array}$} & \multicolumn{7}{|c|}{ COMPARISON OF MELTING RATE OBTAINED BY EXPERIMENTATION ON ROTARY FURNACE \& BY ANFIS MODEL } \\
\hline & \multirow[b]{2}{*}{ Desired } & \multicolumn{2}{|c|}{ Values } & \multirow[b]{2}{*}{ trimf } & \multicolumn{3}{|c|}{ Error in \% } \\
\hline & & gmf & dsigmf & & gmf & dsigmf & trimf \\
\hline 1 & 0.34643 & 0.34641 & 0.34643 & 0.34642 & 0.0000577 & 0.0000000 & 0.0000289 \\
\hline 2 & 0.3333 & 0.33283 & 0.32103 & 0.32734 & 0.0014101 & 0.0368137 & 0.0178818 \\
\hline 3 & 0.35653 & 0.3567 & 0.35652 & 0.35701 & -0.0004768 & 0.0000280 & -0.0013463 \\
\hline 4 & 0.37875 & 0.37858 & 0.37874 & 0.37873 & 0.0004488 & 0.0000264 & 0.0000528 \\
\hline 5 & 0.32724 & 0.32755 & 0.32785 & 0.32806 & -0.0009473 & -0.0018641 & -0.0025058 \\
\hline 6 & 0.34643 & 0.34605 & 0.3464 & 0.34565 & 0.0010969 & 0.0000866 & 0.0022515 \\
\hline 7 & 0.34643 & 0.34599 & 0.34647 & 0.34622 & 0.0012701 & -0.0001155 & 0.0006062 \\
\hline 8 & 0.31815 & 0.31706 & 0.32115 & 0.32363 & 0.0034261 & -0.0094295 & -0.0172246 \\
\hline 9 & 0.32724 & 0.32661 & 0.32338 & 0.32792 & 0.0019252 & 0.0117956 & -0.0020780 \\
\hline 10 & 0.3333 & 0.31314 & 0.30349 & 0.33588 & 0.0604860 & 0.0894389 & -0.0077408 \\
\hline 11 & 0.31815 & 0.31738 & 0.31791 & 0.31783 & 0.0024202 & 0.0007544 & 0.0010058 \\
\hline 12 & 0.3333 & 0.32714 & 0.33072 & 0.32952 & 0.0184818 & 0.0077408 & 0.0113411 \\
\hline 13 & 0.35653 & 0.35653 & 0.35653 & 0.35654 & 0.0000000 & 0.0000000 & -0.0000280 \\
\hline 14 & 0.31815 & 0.3225 & 0.31877 & 0.32863 & -0.0136728 & -0.0019488 & -0.0329404 \\
\hline 15 & 0.3333 & 0.32552 & 0.32945 & 0.33027 & 0.0233423 & 0.0115512 & 0.0090909 \\
\hline 16 & 0.34643 & 0.34347 & 0.34025 & 0.34483 & 0.0085443 & 0.0178391 & 0.0046185 \\
\hline 17 & 0.31815 & 0.33339 & 0.31647 & 0.34261 & -0.0479019 & 0.0052805 & -0.0768820 \\
\hline 18 & 0.32724 & 0.33385 & 0.32618 & 0.32473 & -0.0201992 & 0.0032392 & 0.0076702 \\
\hline 19 & 0.32724 & 0.32972 & 0.32645 & 0.32197 & -0.0075785 & 0.0024141 & 0.0161044 \\
\hline 20 & 0.28785 & 0.28495 & 0.20754 & 0.271 & 0.0100747 & 0.2789995 & 0.0585374 \\
\hline 21 & 0.303 & 0.30356 & 0.31113 & 0.29553 & -0.0018482 & -0.0268317 & 0.0246535 \\
\hline 22 & 0.31815 & 0.31936 & 0.31471 & 0.31122 & -0.0038032 & 0.0108125 & 0.0217822 \\
\hline 23 & 0.26866 & 0.26378 & 0.25929 & 0.26588 & 0.0181642 & 0.0348768 & 0.0103477 \\
\hline 24 & 0.25856 & 0.27568 & 0.27142 & 0.27835 & -0.0662129 & -0.0497370 & -0.0765393 \\
\hline 25 & 0.29492 & 0.30262 & 0.34472 & 0.29242 & -0.0261088 & -0.1688594 & 0.0084769 \\
\hline 26 & 0.25856 & 0.24994 & 0.19449 & 0.25681 & 0.0333385 & 0.2477955 & 0.0067683 \\
\hline
\end{tabular}




\begin{tabular}{|c|c|c|c|c|c|c|c|}
\hline 27 & 0.26866 & 0.27343 & 0.27246 & 0.26776 & -0.0177548 & -0.0141443 & 0.0033500 \\
\hline 28 & 0.29492 & 0.30579 & 0.38318 & 0.29169 & -0.0368575 & -0.2992676 & 0.0109521 \\
\hline 29 & 0.2525 & 0.25346 & 0.26731 & 0.25324 & -0.0038020 & -0.0586535 & -0.0029307 \\
\hline 30 & 0.2626 & 0.25837 & 0.25869 & 0.26175 & 0.0161081 & 0.0148896 & 0.0032369 \\
\hline 31 & 0.2828 & 0.27562 & 0.2827 & 0.27498 & 0.0253890 & 0.0003536 & 0.0276521 \\
\hline 32 & 0.2828 & 0.27429 & 0.27133 & 0.2693 & 0.0300919 & 0.0405587 & 0.0477369 \\
\hline 33 & 0.28785 & 0.28622 & 0.28524 & 0.29088 & 0.0056627 & 0.0090672 & -0.0105263 \\
\hline 34 & 0.31007 & 0.29971 & 0.31314 & 0.29771 & 0.0334118 & -0.0099010 & 0.0398620 \\
\hline 35 & 0.26866 & 0.26893 & 0.26815 & 0.26515 & -0.0010050 & 0.0018983 & 0.0130648 \\
\hline 36 & 0.2828 & 0.28203 & 0.28284 & 0.27798 & 0.0027228 & -0.0001414 & 0.0170438 \\
\hline 37 & 0.2828 & 0.28695 & 0.28502 & 0.28837 & -0.0146747 & -0.0078501 & -0.0196959 \\
\hline 38 & 0.29492 & 0.33199 & 0.31859 & 0.32363 & -0.1256951 & -0.0802591 & -0.0973484 \\
\hline 39 & 0.25856 & 0.25812 & 0.25698 & 0.25806 & 0.0017017 & 0.0061108 & 0.0019338 \\
\hline 40 & 0.2828 & 0.27015 & 0.26349 & 0.25708 & 0.0447313 & 0.0682815 & 0.0909477 \\
\hline 41 & 0.29492 & 0.24051 & 0.29641 & 0.25119 & 0.1844907 & -0.0050522 & 0.1482775 \\
\hline 42 & 0.27472 & 0.26828 & 0.2642 & 0.27041 & 0.0234421 & 0.0382935 & 0.0156887 \\
\hline 43 & 0.28785 & 0.28847 & 0.2875 & 0.2857 & -0.0021539 & 0.0012159 & 0.0074692 \\
\hline 44 & 0.24644 & 0.24564 & 0.24359 & 0.24761 & 0.0032462 & 0.0115647 & -0.0047476 \\
\hline 45 & 0.27472 & 0.28183 & 0.27997 & 0.29383 & -0.0258809 & -0.0191104 & -0.0695617 \\
\hline 46 & 0.28785 & 0.28487 & 0.28273 & 0.28394 & 0.0103526 & 0.0177870 & 0.0135835 \\
\hline 47 & 0.26866 & 0.26777 & 0.2685 & 0.26791 & 0.0033127 & 0.0005955 & 0.0027916 \\
\hline 48 & 0.28785 & 0.28618 & 0.28791 & 0.28953 & 0.0058016 & -0.0002084 & -0.0058364 \\
\hline 49 & 0.29492 & 0.30015 & 0.29597 & 0.29913 & -0.0177336 & -0.0035603 & -0.0142751 \\
\hline 50 & 0.27472 & 0.27973 & 0.28139 & 0.28431 & -0.0182368 & -0.0242793 & -0.0349083 \\
\hline 51 & 0.28785 & 0.27095 & 0.28785 & 0.26806 & 0.0587111 & 0.0000000 & 0.0687511 \\
\hline 52 & 0.2525 & 0.25337 & 0.2611 & 0.2524 & -0.0034455 & -0.0340594 & 0.0003960 \\
\hline 53 & 0.2525 & 0.25447 & 0.27729 & 0.2534 & -0.0078020 & -0.0981782 & -0.0035644 \\
\hline 54 & 0.26866 & 0.27685 & 0.27486 & 0.2754 & -0.0304846 & -0.0230775 & -0.0250875 \\
\hline 55 & 0.28785 & 0.28005 & 0.28071 & 0.28858 & 0.0270974 & 0.0248046 & -0.0025360 \\
\hline 56 & 0.2424 & 0.24044 & 0.24158 & 0.24087 & 0.0080858 & 0.0033828 & 0.0063119 \\
\hline 57 & 0.2828 & 0.28884 & 0.28408 & 0.31788 & -0.0213579 & -0.0045262 & -0.1240453 \\
\hline 58 & 0.303 & 0.30353 & 0.30511 & 0.306 & -0.0017492 & -0.0069637 & -0.0099010 \\
\hline 59 & 0.31007 & 0.30871 & 0.27666 & 0.29702 & 0.0043861 & 0.1077499 & 0.0420873 \\
\hline 60 & 0.29492 & 0.29379 & 0.30306 & 0.29136 & 0.0038315 & -0.0276007 & 0.0120711 \\
\hline 61 & 0.2626 & 0.26559 & 0.26329 & 0.2675 & -0.0113861 & -0.0026276 & -0.0186596 \\
\hline 62 & 0.2828 & 0.27731 & 0.27762 & 0.28118 & 0.0194130 & 0.0183168 & 0.0057284 \\
\hline 63 & 0.25856 & 0.24836 & 0.19849 & 0.25547 & 0.0394493 & 0.2323252 & 0.0119508 \\
\hline 64 & 0.28785 & 0.27888 & 0.28084 & 0.28306 & 0.0311621 & 0.0243530 & 0.0166406 \\
\hline 65 & 0.24644 & 0.24475 & 0.24029 & 0.24485 & 0.0068577 & 0.0249554 & 0.0064519 \\
\hline 66 & 0.26866 & 0.2662 & 0.27378 & 0.26218 & 0.0091566 & -0.0190575 & 0.0241197 \\
\hline 67 & 0.2424 & 0.23878 & 0.24155 & 0.24 & 0.0149340 & 0.0035066 & 0.0099010 \\
\hline 68 & 0.26866 & 0.26817 & 0.26683 & 0.26983 & 0.0018239 & 0.0068116 & -0.0043549 \\
\hline 69 & 0.2828 & 0.28286 & 0.2974 & 0.27905 & -0.0002122 & -0.0516266 & 0.0132603 \\
\hline
\end{tabular}

TABLE : 4

Melting Rate obtained by Experiment on Rotary Furnace using Bio-fuel showing relationship with various parameter used in ANFIS model

\begin{tabular}{|l|l|l|l|l|l|l|l|}
\hline $\begin{array}{l}\text { Sl. } \\
\text { No. }\end{array}$ & $\begin{array}{l}\text { Excess } \\
\text { Air } \\
(\%)\end{array}$ & $\begin{array}{l}\text { Flame } \\
\text { Temperature } \\
\left({ }^{\circ} \mathbf{C}\right)\end{array}$ & $\begin{array}{l}\text { Rotational } \\
\text { Speed } \\
(\mathbf{R P M})\end{array}$ & $\begin{array}{l}\text { Melting Time } \\
(\text { Minutes })\end{array}$ & $\begin{array}{l}\text { Preheat Air } \\
\text { Temperature } \\
\left({ }^{\circ} \mathbf{C}\right)\end{array}$ & $\begin{array}{l}\text { Fuel } \\
\text { Consumed } \\
(\text { Liters })\end{array}$ & $\begin{array}{l}\text { Experimental Values of } \\
\text { Melting Rate } \\
(\mathbf{M T} / \text { Hr. })\end{array}$ \\
\hline 1 & 10 & 2212 & 0.8 & 36 & 200 & 77 & 0.34643 \\
\hline 2 & 10 & 2217 & 0.8 & 37 & 200 & 76 & 0.3333 \\
\hline 3 & 10 & 2222 & 0.8 & 35 & 300 & 76 & 0.35653 \\
\hline 4 & 10 & 2303 & 0.8 & 33 & 400 & 75 & 0.37875 \\
\hline 5 & 10 & 2197 & 1 & 38 & 200 & 79 & 0.32724 \\
\hline 6 & 10 & 2222 & 1 & 36 & 300 & 77 & 0.34643 \\
\hline 7 & 10 & 2293 & 1 & 35 & 400 & 76 & 0.34643 \\
\hline 8 & 10 & 2187 & 1.2 & 39 & 200 & 79 & 0.31815 \\
\hline
\end{tabular}




\begin{tabular}{|c|c|c|c|c|c|c|c|}
\hline 9 & 10 & 2207 & 1.2 & 38 & 300 & 79 & 0.32724 \\
\hline 10 & 10 & 2267 & 1.2 & 37 & 400 & 76 & 0.3333 \\
\hline 11 & 10 & 2177 & 1.4 & 39 & 200 & 81 & 0.31815 \\
\hline 12 & 10 & 2202 & 1.4 & 37 & 300 & 82 & 0.3333 \\
\hline 13 & 10 & 2262 & 1.4 & 35 & 400 & 80 & 0.35653 \\
\hline 14 & 10 & 2172 & 1.6 & 39 & 200 & 81 & 0.31815 \\
\hline 15 & 10 & 2200 & 1.6 & 37 & 300 & 80 & 0.3333 \\
\hline 16 & 10 & 2237 & 1.6 & 36 & 400 & 79 & 0.34643 \\
\hline 17 & 10 & 2131 & 2 & 39 & 200 & 81 & 0.31815 \\
\hline 18 & 10 & 2156 & 2 & 38 & 300 & 80 & 0.32724 \\
\hline 19 & 10 & 2192 & 2 & 38 & 400 & 79 & 0.32724 \\
\hline 20 & 20 & 2010 & 0.8 & 43 & 200 & 79 & 0.28785 \\
\hline 21 & 20 & 2086 & 0.8 & 41 & 300 & 79 & 0.303 \\
\hline 22 & 20 & 2151 & 0.8 & 39 & 400 & 79 & 0.31815 \\
\hline 23 & 20 & 1959 & 1.2 & 46 & 200 & 85 & 0.26866 \\
\hline 24 & 20 & 2005 & 1.2 & 44 & 300 & 84 & 0.25856 \\
\hline 25 & 20 & 2040 & 1.2 & 42 & 400 & 82 & 0.29492 \\
\hline 26 & 20 & 1858 & 1.4 & 48 & 200 & 85 & 0.25856 \\
\hline 27 & 20 & 1909 & 1.4 & 46 & 300 & 83 & 0.26866 \\
\hline 28 & 20 & 1970 & 1.4 & 42 & 400 & 81 & 0.29492 \\
\hline 29 & 20 & 1737 & 1.6 & 49 & 200 & 87 & 0.2525 \\
\hline 30 & 20 & 1808 & 1.6 & 47 & 300 & 85 & 0.2626 \\
\hline 31 & 20 & 1838 & 2 & 44 & 400 & 83 & 0.2828 \\
\hline 32 & 30 & 1924 & 0.8 & 44 & 200 & 81 & 0.2828 \\
\hline 33 & 30 & 2015 & 0.8 & 43 & 300 & 80 & 0.28785 \\
\hline 34 & 30 & 2121 & 0.8 & 40 & 400 & 78 & 0.31007 \\
\hline 35 & 30 & 1990 & 1 & 46 & 200 & 82 & 0.26866 \\
\hline 36 & 30 & 2030 & 1 & 44 & 300 & 81 & 0.2828 \\
\hline 37 & 30 & 1985 & 1.2 & 44 & 300 & 82 & 0.2828 \\
\hline 38 & 30 & 2020 & 1.2 & 42 & 400 & 80 & 0.29492 \\
\hline 39 & 30 & 1833 & 1.4 & 48 & 200 & 86 & 0.25856 \\
\hline 40 & 30 & 1889 & 1.4 & 44 & 300 & 83 & 0.2828 \\
\hline 41 & 30 & 1985 & 1.4 & 42 & 400 & 82 & 0.29492 \\
\hline 42 & 30 & 1783 & 1.6 & 45 & 300 & 84 & 0.27472 \\
\hline 43 & 30 & 1808 & 1.6 & 43 & 400 & 83 & 0.28785 \\
\hline 44 & 30 & 1752 & 2 & 50 & 200 & 88 & 0.24644 \\
\hline 45 & 40 & 1914 & 0.8 & 45 & 200 & 81 & 0.27472 \\
\hline 46 & 40 & 1990 & 0.8 & 43 & 300 & 80 & 0.28785 \\
\hline 47 & 40 & 1975 & 1 & 46 & 200 & 82 & 0.26866 \\
\hline 48 & 40 & 2015 & 1 & 43 & 300 & 81 & 0.28785 \\
\hline 49 & 40 & 2081 & 1 & 42 & 400 & 80 & 0.29492 \\
\hline 50 & 40 & 1964 & 1.2 & 45 & 300 & 82 & 0.27472 \\
\hline 51 & 40 & 2015 & 1.2 & 43 & 400 & 82 & 0.28785 \\
\hline 52 & 40 & 1808 & 1.4 & 49 & 200 & 85 & 0.2525 \\
\hline 53 & 40 & 1727 & 1.6 & 49 & 200 & 85 & 0.2525 \\
\hline 54 & 40 & 1762 & 1.6 & 46 & 300 & 83 & 0.26866 \\
\hline 55 & 40 & 1793 & 1.6 & 43 & 400 & 81 & 0.28785 \\
\hline 56 & 40 & 1737 & 2 & 51 & 200 & 88 & 0.2424 \\
\hline 57 & 50 & 1879 & 0.8 & 44 & 200 & 81 & 0.2828 \\
\hline
\end{tabular}




\begin{tabular}{|l|l|l|l|l|l|l|l|}
58 & 50 & 1975 & 0.8 & 41 & 300 & 80 & 0.303 \\
\hline 59 & 50 & 2060 & 0.8 & 40 & 400 & 79 & 0.31007 \\
\hline 60 & 50 & 2020 & 1 & 42 & 400 & 81 & 0.29492 \\
\hline 61 & 50 & 1904 & 1.2 & 47 & 200 & 83 & 0.2626 \\
\hline 62 & 50 & 1934 & 1.2 & 44 & 300 & 81 & 0.2828 \\
\hline 63 & 50 & 1788 & 1.4 & 48 & 200 & 84 & 0.25856 \\
\hline 64 & 50 & 1939 & 1.4 & 43 & 400 & 81 & 0.28785 \\
\hline 65 & 50 & 1712 & 1.6 & 50 & 200 & 87 & 0.24644 \\
\hline 66 & 50 & 1752 & 1.6 & 46 & 300 & 84 & 0.26866 \\
\hline 67 & 50 & 1722 & 2 & 51 & 200 & 88 & 0.2424 \\
\hline 68 & 50 & 1768 & 2 & 46 & 300 & 84 & 0.26866 \\
\hline 69 & 50 & 1778 & 2 & 44 & 400 & 83 & 0.2828 \\
\hline
\end{tabular}

